\title{
A ESCOLA PÚBLICA E SEU ENTORNO SOCIAL - UMA QUESTÃO EM ABERTO
}

\section{THE PUBLIC SCHOOL AND ITS SOCIAL ENVIRONMENT - AN OPEN QUESTION}

\author{
VIEIRA, Sofia Lerche \\ sofialerche@gmail.com \\ UNINOVE- Universidade Nove de Julho \\ VIDAL, Eloisa Maia \\ eloisamvidal@yahoo.com.br \\ UECE- Universidade Estadual do Ceará
}

\begin{abstract}
RESUMO Este artigo procura aproximar-se do tema escola, família e comunidade do seu entorno, buscando por meio de uma incursão na literatura, estudos e relatos, refletir sobre essa complexa relação. Procura também identificar possíveis matrizes geradoras que a orientam no cenário da política educacional brasileira. A presença de iniciativas que envolvem a relação entre a escola e seu entorno no país nem sempre foi foco de ação deliberada por parte do poder público. Apenas a partir de meados dos anos noventa do século XX surgem iniciativas que, direta ou indiretamente, envolvem esta relação, como o Programa Dinheiro Direto na Escola (PDDE), o Programa Nacional de Fortalecimento dos Conselhos Escolares e o Programa Escola Aberta. O trabalho analisa ainda, dados de pesquisas acerca da visão de diretores e professores sobre a matéria, partindo de duas diferentes fontes de informação: Questionário do Diretor e Questionário do Professor da Prova Brasil 2011. Esta avaliação de larga escala é aplicada pelo Ministério da Educação, junto aos alunos da educação básica pública, e inclui questionários contextuais aplicados a diretores e professores. Neles, foram identificadas 19 questões envolvendo algum tipo de indagação sobre a relação escola e família e dados obtidos em projeto de investigação sobre 15 municípios na região do Maciço de Baturité - Ceará, desenvolvido com financiamento do CNPq. Os dados confirmam o caráter positivo dessa relação, mostrando, entretanto, que a relação entre a escola e a família aparece como uma questão assimétrica e em aberto. Em outros termos, um nó ainda não suficientemente dissolvido.
\end{abstract}

PALAVRAS-CHAVE: Escola Pública. Maciço de Baturité. Prova Brasil 2011.Relaçãoescola-família.

ABSTRACT This article aims at approaching the theme school, family and community through a review in the literature, studies and reports and at reflecting on this complex relationship. It also tries to identify possible reasons that guide this relationship in the Brazilian educational policy scenario. The relations that involve school and community have not always been the focus of deliberate action by the Government in this country. It was only from the mid-nineties of the 20th century on that the Government has focused on actions that directly or indirectly relate this relationship: The Direct Money in School Program (PDDE), the National Program for the Strengthening of the School Boards, and the Open School Program. This paper also analyses the data about the view of directors and teachers on the subject, starting from two different sources of information: data from the questionnaires of the 
Director and the questionnaires of the Teacher of the 2011 Prova Brazil, a large scale evaluation is applied in the fifth and the ninth grades students of public elementary school and includes contextual questionnaires applied to directors and teachers in which there were 19 questions identified as involving something about the relationship between school and family; and an investigation project on 15 cities of the Maciço de Baturité, a northern region in the State of Ceara, developed with funding from the National Council for Scientific and Technological Development (CNPq). The data confirm the positive character of this relationship, showing, however, that the relationship between school and family appears as an asymmetric question and still open. In other words, a knot still untied.

KEYWORDS: Maciço de Baturité. Prova Brazil 2011.School-family relationship.

\section{INTRODUÇÃO}

O todo é maior que a parte.

(Euclides, Elementos)

A reflexão sobre a escola e seu entorno social comporta algumas questões (im)pertinentes. Em primeiro lugar, trata-se de um tema incorporado ao debate sobre a escola pública em tempos recentes. As famílias das chamadas classes média e alta sempre acompanharam, e continuam acompanhando, a vida escolar de seus filhos nas escolas que frequentam, na medida de seus interesses e disponibilidades. No entanto, essa agenda tem especial relevância se considerarmos que na rede escolar pública encontra-se $83,0 \%$ dos 44.972 .696 milhões de estudantes das três etapas da educação básica (INEP, 2013) ${ }^{1}$ brasileira.

A conexão entre a escola e seu entorno social, por meio de mecanismos diversos de representação comunitária e da participação das famílias, tem sido objeto de atenção, justamente com base no argumento de que das famílias depende boa parte do sucesso escolar dos estudantes. Neste caso, sua mobilização é fator estratégico para reverter o estigma do fracasso escolar que tende a perseguir as crianças oriundas dos extratos sociais mais empobrecidos da população.

Uma segunda questão a destacar é que apenas muito recentemente a escola pública passou a ser um bem cultural disponível às famílias das crianças, que hoje

\footnotetext{
${ }^{1}$ Estes números referem-se à matrícula em Educação Infantil, Ensino Fundamental e Ensino Médio, excluindo Educação de Jovens e Adultos, Educação Profissional e Educação Especial e outras modalidades.
} 
transpõem suas portas. Para muitos que vivem no território em seu entorno, portanto, a escola ainda é cercada da mística do que não se conhece e acaba por constituir-se como uma caixa-preta. Quando a família e a comunidade se sentem intimidados perante a escola e seus professores, esta relação torna-se mais complexa.

Uma terceira questão a lembrar, é que a escola pública é marcada por uma miríade de faces, expressão de um Brasil diverso, contraditório e complexo. As políticas que chegam às escolas são concebidas numa visão de totalidade. Longe estão, porém, de comportar as peculiaridades dos diferentes entornos, das violentas periferias urbanas, as empobrecidas populações do interior do território brasileiro. Não é a mesma, por certo, a relação que cada uma dessas escolas, em suas especificidades, estabelece com sua circunvizinhança. Este, sem dúvida, é mais um componente a desafiar a complexa teia em que se entrelaça a escola e a comunidade ao ser redor.

Este artigo procura aproximar-se deste instigante tema mediante um percurso que compreende: uma incursão na literatura sobre a relação escola-famíliacomunidade; uma identificação de possíveis matrizes geradoras desta discussão no cenário da política educacional brasileira; um exame de iniciativas de política voltadas para a escola e seu entorno; e, finalmente, alguns recortes de como tais problemas são percebidos por atores nem sempre ouvidos na formulação de políticas - as famílias e as próprias escolas. Aqui, as autoras se debruçam sobre a base de dados dos Questionários do Diretor e Professor, integrantes da Prova Brasil 2011, recortando as questões que envolvem algum tipo de indagação sobre a relação escola e família; apresentam ainda reflexões a partir de dados obtidos em pesquisas que têm desenvolvido com foco nas interfaces entre a escola e seus usuários, a gestão e a política educacional. Como recurso metodológico, são formuladas perguntas que abrem caminho à considerações. Estas, por sua vez, encadeiam uma lógica onde as partes se articulam mutuamente e, juntas, compõem o todo que se procura desvelar. Passemos, pois, à primeira indagação.

\section{QUE DIZ A LITERATURA?}


A discussão sobre a importância da escola e seu entorno, ou da relação escola-família-comunidade, como alguns autores preferem, não tem sido um tema de destaque na produção acadêmica em política educacional no Brasil. De uma maneira geral, a literatura tem se debruçado pouco sobre os meandros dessa trama de complexas relações. Sem pretender incorrer no terreno das explicações para as razões que têm relegado esta problemática a um segundo plano na reflexão teórica sobre as questões relativas à escola, caberia a pergunta: onde estariam abrigados, então, os estudos sobre o tema?

Há, com efeito, um debate fecundo a respeito do tema nos estudos sobre eficácia escolar que começam a surgir na literatura internacional a partir de meados dos anos sessenta do século XX, onde um primeiro e importante "marco de pesquisa sociológica" sobre o tema foi o Relatório Coleman (BROOKE; SOARES, 2008, p. 2632). Nesse cenário é oportuno mencionar também o Relatório Plowden, da Inglaterra, com um capítulo específico sobre "O Lar, a Escola e a Vizinhança" (BROOKE; SOARES, 2008, p. 67-73). No Brasil, tais investigações são bem mais tardias, surgindo nos anos noventa, a partir de quando passam a despertar interesse de organismos governamentais e não governamentais. Neste caso, embora desenvolvidas por pesquisadores de universidades, em sua maioria, são financiadas com apoio externo e não figuram na pauta dos interesses acadêmicos.

O contato com a revisão sobre o tema (NYE; SCHWARTZ; TURNER, 2006) revela que nos primeiros anos de investigação a respeito do assunto, grande parte das pesquisas internacionais foram de natureza qualitativa, embora mais recentemente, tenha aumentado a presença da abordagem quantitativa. Os estudos evidenciam controvérsias sobre a própria definição do que seja participação e envolvimento familiar. Embora nem sempre seja passível de comprovação, o caráter positivo de tal envolvimento parece predominar o entendimento de que este elemento contribui para a melhoria do desempenho das crianças.

É verdade que a participação das famílias tem sido referida como importante elemento associado à eficácia escolar, particularmente em contextos de pobreza. Uma das constatações do estudo Goodschools in poorneighborhoods(CLEWELL; CAMPBELL; PERLMAN, 2007, p. 172-173) aponta nesse sentido, indicando 
explicitamente como recomendação de política que "o envolvimento de pais é crucial".

Vale assinalar que a recomendação sobre o nexo escola-família não merece semelhante atenção em outros estudos. Em revisão sobre o tema, Eyzaguirre (2004, p. 251) destaca que nem todos os estudos confirmam a importância da participação dos pais, ao mesmo tempo em que defende a concentração do foco do trabalho escolar sobre a aprendizagem dos estudantes:

la participación de los padres, que no la traté porque no todos los estudios la confirman y porque considero que la coordinación de los padres es muy demandante en tempo para los equipos directivos y, por ende, se corre el riego de que dejen de lado sus funciones de liderar lo académico ${ }^{2}$.

Como se vê, o tema é de natureza polêmica; possui prós e contras. Assim, vale a pena avançar um tanto mais na reflexão, buscando a forma como este tem sido apropriado por organismos que, de uma forma ou de outra, têm potencial de influência sobre a formulação de políticas educacionais. Isto nos remete a algumas das matrizes geradoras dos argumentos em favor da articulação entre a escola e seu entorno nas últimas décadas.

\section{QUAIS SÃO AS MATRIZES GERADORAS DESTA DISCUSSÃO?}

Numa reconstituição da origem histórica do debate sobre esta temática, seria oportuno assinalar como marco a Conferência de Jomtien (1990), cujo documento final, "A Declaração Mundial de Educação para Todos", trata de "fortalecer as alianças" (Art. 7):

Novas e crescentes articulações e alianças serão necessárias em todos os níveis: entre todos os subsetores e formas de educação, reconhecendo o papel especial dos professores, dos administradores e do pessoal que trabalha em educação; entre os órgãos educacionais e demais órgãos de governo, incluindo os de planejamento, finanças, trabalho, comunicações, e outros setores sociais; entre as organizações governamentais e não governamentais, com o setor privado, com as comunidades locais, com os grupos religiosos, com as famílias. É particularmente importante reconhecer

\footnotetext{
${ }^{2}$ Não tratei da participação dos pais porque nem todos os estudos a confirmam e porque considero que a coordenação dos pais demanda muito tempo das equipes diretivas e consequentemente, exige que deixem de lado suas atribuições de liderar as questões pedagógicas.
} 
o papel vital dos educadores e das famílias(UNESCO, 1990, p. 4-5, grifo nosso).

Na esteira de tais preocupações, agências internacionais como a Unesco e o Banco Mundial apoiaram a realização de estudos, publicações e iniciativas de intervenção. Dadas as limitações de tempo da exposição, merece registro um breve anuncio de tal movimento.

\subsection{UNESCO}

Uma das primeiras publicações da Unesco sobre a relação escola-famíliacomunidade foi o livro Participation for educationalchange: a synthesis of experience ,de Shaeffer (1994). A esse se somaram outras, a exemplo do estudo elaborado por Rose (2003), visando o Relatório de Monitoramento Global da Unesco. Outras iniciativas merecem registro, como o livreto de Redding (s/d), disponível online e cuja tradução e divulgação são autorizadas pela instituição. Por certo, uma pesquisa mais minuciosa poderia ampliar o leque de contribuições disponíveis, permitindo melhor entender a esfera de abrangência do interesse da Unesco pelo tema e a capilaridade dos estudos, artigos e livros que a instituição tem apoiado.

No Brasil, sua aproximação ao tema explicitou-se em duas direções: de um lado, pela concepção do programa Escola Aberta, tratado adiante; de outro, pelo apoio a publicações ora disponíveis em seu portal (ATHIAS, 2008; CASTRO; REGATTIERI,2009).

\subsection{BANCO MUNDIAL}

Igualmente importante e de natureza diversa tem sido o interesse do Banco Mundial pelo tema. Pesquisando na web, descritores relativos à participação de pais e da comunidade na escola ("parente involvement" e "community participation") em associação com o nome deste organismo ("World Bank"),é possível localizar referências a estudos e artigos (GERTLER; PATRINOS;RUBIO-CODINA, 2008;UEMURA, 1999), assim como projetos desenvolvidos com o apoio financeiro deste organismo. 
Em um inventário realizado em 1999 (UEMURA, p. 15-26), foram registradas diversas iniciativas com a presença de um componente de participação em projetos em diferentes países: Chade (Basic Education Project - Education V), Ghana (Community Secondary Schools Construction Project), Malawi (Primary Education Project), Tanzânia (Human Resources Development Pilot Project), Bolívia (Education Reform Project), República Dominicana (Primary Education Development Project), El Salvador (EDUCO: Basic Education Modernization Project in El Salvador) e Honduras (Honduras Basic Education Project). O mesmo documento refere 15 outros projetos do Banco com foco no tema (UEMURA, 1999, p. 26-32).

O interesse pelo tema em relação a projetos desenvolvidos no Brasil pode ser identificado por meio de estudos realizados no âmbito do Projeto Nordeste e de preparação para o Fundescola, assim como componentes de projetos desenvolvidos, em contrapartida, com governos estaduais e municipais.

\subsection{OUTRAS ORGANIZAÇÕES}

a) Todos pela Educação: para além da influência desses dois organismos internacionais, no Brasil vale citar ainda o destaque dado ao tema pelo Movimento Todos pela Educação, que divulga um material denominado: "eu, você, todos pela educação - participação dos pais". Como se vê, há um interesse por parte de organizações influentes no cenário da educação brasileira sobre a relação escola e seu entorno.

b) Parents participation: para concluir a resposta à indagação sobre as matrizes que têm alimentado o debate sobre a escola e seu entorno, é importante destacar a iniciativa Parents participation, um observatório da União Europeia, que visa monitorar o envolvimento dos pais na educação, a partir de um conjunto de indicadores denominados IPPE (Indicators of Parental Involvement in Compulsory Education). Trata-se de um projeto de pesquisa desenvolvido por um consórcio de universidades e organizações da sociedade civil e está presente em diversos países, como Reino Unido, França, Espanha, Portugal, Suíça, Suécia e outros.

Certo é que, tendo surgido como um tema direcionado aos países que se configuram como alvo de atenção dos organismos internacionais, inserido nas 
recomendações da Conferência de Jomtien, a escola e seu entorno hoje fazem parte de uma agenda global para a educação.

De modo a prosseguir na reflexão, vale a pena examinar como a questão passa a integrar o rol de preocupações das políticas educacionais no Brasil. Assim, é oportuno passar à próxima pergunta.

\section{QUE POLÍTICAS EXPRESSAM TAIS PREOCUPAÇÕES?}

A presença de iniciativas que envolvem a relação entre a escola e seu entorno no Brasil nem sempre foi foco de ação deliberada por parte do poder público. Por volta de meados dos anos noventa, este cenário começa a mudar. Aqui, merecem destaque três iniciativas de política educacional que, direta ou indiretamente, envolvem a escola em sua relação com as famílias e a comunidade: o Programa Dinheiro Direto na Escola (PDDE), o Programa Nacional de Fortalecimento dos Conselhos Escolares e o Programa Escola Aberta. Vejamos de forma resumida a que se referem.

\subsection{PROGRAMA DINHEIRO DIRETO NA ESCOLA}

No inicio do primeiro governo Fernando Henrique Cardoso (1995-1998), foi criada uma iniciativa de repasse de recursos federais à escolas públicas, que veio a ser conhecido como Programa Dinheiro Direto na Escola (PDDE). Dentre as exigências a cumprir para o recebimento de recursos, estava prevista a criação de Unidades Executoras que, na prática, eram constituídas por Conselhos Escolares, encarregados da gestão dos referidos repasses.

Criado em 1995, os recursos do PDDE originalmente atendiam apenas escolas públicas de ensino fundamental, tendo sido ampliados para toda a educação básica a partir de 2009, quando passaram a contemplar também escolas particulares com atendimento em educação especial. Segundo informações disponíveis no portal do Ministério da Educação (MEC), o orçamento do programa em 2013 chegou a R\$ 2,2 bilhões. Originalmente, os recursos eram destinados a prestar assistência financeira suplementar com o objetivo de promover a melhoria da 
infraestrutura física das escolas. Com sua ampliação, passaram a apoiar também ações de natureza pedagógica "a fim de favorecer a melhoria da qualidade de ensino e a promoção da sustentabilidade socioambiental nas unidades escolares" (Art 10, RESOLUÇÃO no 18/2014).

Induzidos por um fator externo, os Conselhos Escolares foram criados e passaram a fazer parte do cotidiano da gestão escolar, independentemente do interesse ou vontade dos profissionais da educação. Um grande número de unidades passaram a constituir-se como importante mecanismo de empoderamento das famílias e das comunidades. Para que isto ocorresse, foi estratégica outra medida de indução do governo federal, a saber: a criação do Programa Nacional de Fortalecimento dos Conselhos Escolares, já no governo Lula. Passemos a um rápido exame de suas características.

\subsection{PROGRAMA NACIONAL DE FORTALECIMENTO DOS CONSELHOS ESCOLARES}

Este programa tem

por objetivo fomentar a implantação dos conselhos escolares, por meio da elaboração de material didático específico e formação continuada, presencial e a distância, para técnicos das Secretarias Estaduais e Municipais de educação e para conselheiros escolares, de acordo com as necessidades dos sistemas de ensino, das políticas educacionais e dos profissionais de educação envolvidos com gestão democrática (Disponível em:<http://portal.mec.gov.br/index.php?option=com_content\&view=arti cle\&id=12384: conselhos-escolares-apresentacao\&catid=316: conselhosescolares\&lte mid=655>. Acesso em: 18 out. 2014).

Trata-se de um conjunto de 12 cadernos que podem ser utilizados, no todo ou em parte, para a formação e, como o próprio nome diz, fortalecimento dos conselhos escolares. Disponíveis em livre acesso no portal do MEC, as publicações versam sobre temas diversos ligados à criação, papel e áreas de atuação dos conselhos, desde sua importância para a gestão democrática, até questões próprias da aprendizagem, relação entre a comunidade e a escola, aproveitamento do tempo pedagógico, escolha de diretores, dentre outros. 
Segundo o site do MEC, no período 2005 a 2011, foram capacitados 11.973 conselheiros e técnicos das secretarias de educação em cursos de extensão oferecidos na modalidade a distância ${ }^{3}$ e 18.761 pessoas participaram de encontros presenciais de Formação do Programa Nacional de Fortalecimento dos Conselhos Escolares ${ }^{4}$.

Além das publicações, o Ministério disponibiliza aos usuários o acesso a um Banco de Experiências de Conselhos Escolares, onde estão cadastradas 180 iniciativas ${ }^{5}$. Considerando a existência de 27 estados, é interessante observar que alguns se destacam pelo número de registros, caso de São Paulo (39), Ceará (32) e Rio Grande do Sul (25); os demais têm, em média, uma a duas iniciativas, por vezes um pouco mais.

\title{
4.3 PROGRAMA ESCOLA ABERTA
}

Concebido originalmente pela Unesco que estabeleceu convênios com governos estaduais, a exemplo de Rio de Janeiro, São Paulo e Pernambuco (ATHIAS, 2008), o Programa Escola Aberta foi incorporado pelo MEC. Consiste em ação de incentivo e apoio

\begin{abstract}
à abertura, nos finais de semana, de unidades escolares públicas localizadas em territórios de vulnerabilidade social. A estratégia potencializa a parceria entre escola e comunidade ao ocupar criativamente o espaço escolar aos sábados e/ou domingos com atividades educativas, culturais, esportivas, de formação inicial para o trabalho e geração de renda oferecidas aos estudantes e à população do entorno ${ }^{6}$.
\end{abstract}

O programa proporciona a abertura das escolas nos finais de semana, funcionando como espaço alternativo para o desenvolvimento de atividades de formação para os alunos da educação básica das escolas públicas e comunidade no

\footnotetext{
${ }^{3}$ Disponível em:

<http://portal.mec.gov.br/index.php?option=com_content\&view=article\&id=14805\&ltemid=1054>. Acesso em: 18 out. 2014.

${ }^{4}$ Disponível

<http://portal.mec.gov.br/index.php?option=com_content\&view=article\&id=14805\&ltemid=1054>.

em: Acesso em: 18 out. 2014.

${ }^{5}$ Disponível em: <http://bancodeexperienciasce.mec.gov.br/relato/lista>. Acesso em: 18 out. 2014.

${ }^{6}$ Disponível em:<http://portal.mec.gov.br/index.php?option=com_content\&view=article\&id=16739\&lte mid=811>. Acesso em: 18 out. 2014.
} 
entorno. Os recursos financeiros são transferidos às escolas e destinados às despesas de capital e de custeio necessárias à realização das oficinas, bem como ao pagamento de horas-aula para os oficineiros ${ }^{7}$, além do ressarcimento das despesas com alimentação e transporte para um "coordenador escolar", pessoa da comunidade que fica responsável pelo funcionamento da escola durante todo o final de semana. O principal objetivo é estreitar as relações entre escola e comunidade, contribuindo para a consolidação de uma cultura de paz.

A existência de três programas do governo federal, visando melhor aproximação entre a escola e seu entorno, é uma evidência da percepção do caráter estratégico desta relação por parte dos formuladores de políticas. Resultados de pesquisas mostram que os agentes educativos reconhecem 0 valor de tais iniciativas, estes responderam afirmativamente sobre sua importância. Entretanto, muitas são as nuances desta relação. O próximo tópico aprofunda o tema mediante análise de dados de pesquisa em que gestores escolares e professores se manifestam sobre a matéria.

\section{O QUE SE PODE APRENDER COM DADOS DE PESQUISA?}

Os dados de pesquisa oferecem pistas interessantes sobre a visão de diretores e professores acerca da relação escola-família-comunidade. A reflexão procura aproximar duas diferentes fontes de informação: em um primeiro momento são discutidos dados dos questionários do diretor e professor aplicados quando da realização da Prova Brasil 2011, uma avaliação de larga escala, de periodicidade bianual, aplicada pelo governo federal junto às escolas públicas de ensino fundamental para as disciplinas de Língua Portuguesa e Matemática e que inclui questionários contextuais aplicados junto a diretores e professores das disciplinas citadas. Em seguida, aprofundam-se informações, a partir de estudos qualitativos decorrentes de pesquisa de campo realizada pelas autoras numa região geográfica do estado do Ceará, composta de 15 municípios, durante dois anos, tomando com

\footnotetext{
${ }^{7}$ Oficineiros são pessoas da própria comunidade que têm algo a ensinar, por meio de oficinas, com cerca de quatro horas de duração, nos finais de semana. São comuns oficinas de confecção de materiais diversos (adornos e outros materiais), danças (hip-hop, capoeira, dança de rua), e outros saberes valorizados pelo grupo local.
} 
amostra duas escolas em cada município: uma de alto Ideb e uma de baixo Ideb (VIDAL; VIEIRA, 2014; VIDAL; VIEIRA; MEDEIROS, 2014).

A Prova Brasil coleta um conjunto de informações acerca de diretores e professores de Língua Portuguesa e Matemática que atuam nos $5^{\circ}$ e $9^{\circ}$ anos de escolas públicas de ensino fundamental. Em 2011, este instrumento foi aplicado junto a 56.222 diretores e 304.412 professores $^{8}$.Do questionário do diretor, com 212 perguntas, 16 questões tratam da atuação/participação da comunidade junto à escola. Do questionário do professor, com 152 perguntas, apenas 3 envolvem algum tipo de relação da escola com a família, e todas referentes a dificuldades no processo ensino-aprendizagem, como se verá adiante.

Uma indagação presente no questionário do diretor se refere à presença dos pais na composição do Conselho Escolar. Do total, $83,8 \%$ afirmam que os pais compõem o Conselho Escolar e apenas 2,7\% informam que os pais não participam do Conselho, $13,3 \%$ não responderam e 0,1\% anularam a resposta. Isso mostra que a grande maioria das escolas considera relevante a participação dos pais neste tipo de organismo colegiado e atende à orientação da legislação brasileira sobre a "participação das comunidades escolar e local em conselhos escolares ou equivalentes"(LDB, Art. 14, II).

Uma segunda indagação se refere ao número de vezes que o Conselho Escolar se reúne por ano e os resultados são apresentados no gráfico 1.

Gráfico 1 - Número de reuniões do Conselho Escolar por ano

\footnotetext{
${ }^{8}$ Os dados analisados encontram-se para download no site do Inep, disponível em: <http://portal.inep.gov.br/basica-levantamentos-acessar>. Acesso em: 18 out. 2014.
} 


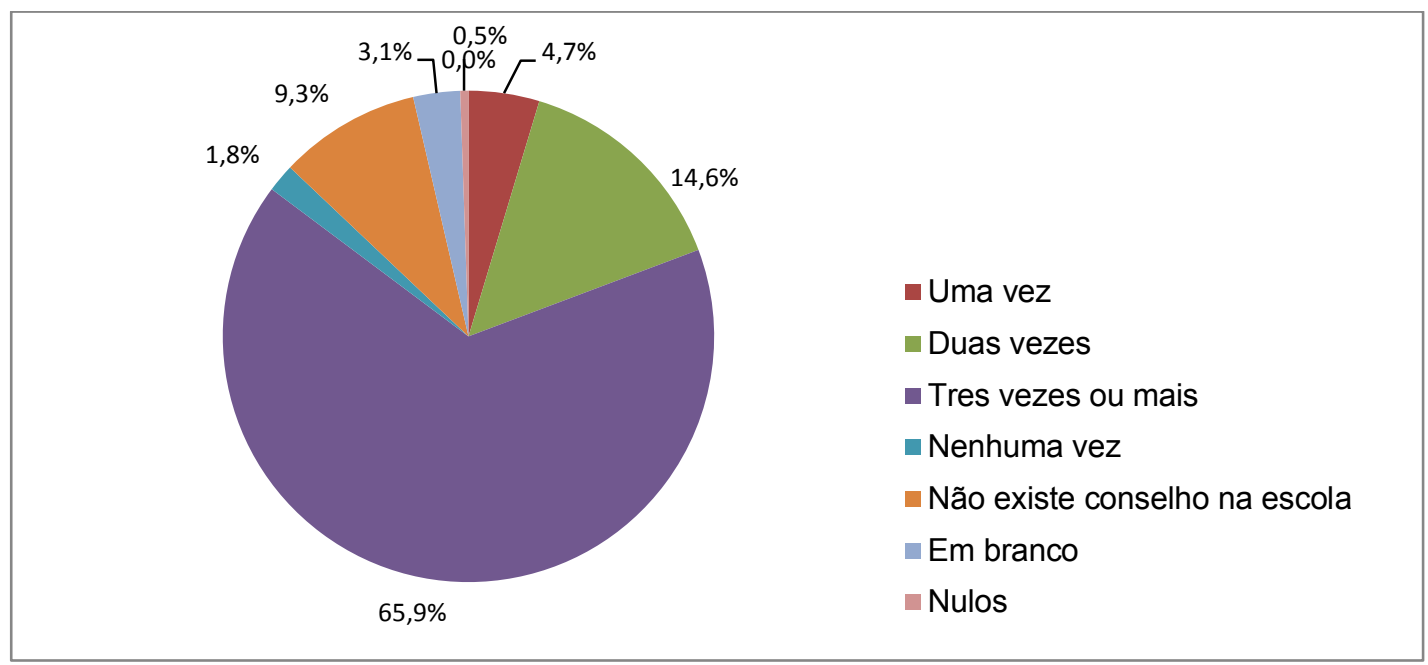

Fonte: Elaboração das autoras, 2014

Os dados mostram que na maioria das escolas, o Conselho Escolar se reúne entre duas vezes $(14,6 \%)$ e três vezes ou mais $(65,9 \%)$, totalizando $80,6 \%$ dos estabelecimentos pesquisados. Chama a atenção, o fato de 5.238 escolas públicas $(9,3 \%)$ informarem que não possuem Conselho Escolar, que somados aos 1,8\% das escolas que informaram que o Conselho Escolar não se reúne nenhuma vez, totaliza $11,1 \%$ dos estabelecimentos de ensino pesquisados. Esses dados podem indicar fragilidades no processo de gestão democrática e participativa, que conforme preconiza a Constituição de 1988 e a LDB de 1996 para as escolas públicas, se efetiva na organização e funcionamento deste colegiado.

Os diretores foram também indagados sobre o desenvolvimento do projeto pedagógico da escola no ano de 2011 e 40,7\% responderam que o referido projeto foi concebido por "professores, pais, outros servidores, estudantes e a própria direção da escola", confirmando a participação da família nesta iniciativa que é o coração da escola e que dá sua identidade, define sua missão e estabelece seus valores.

No que diz respeito à frequência por parte das crianças e jovens na escola, foi indagado aos diretores sobre as atitudes adotadas para evitar que os alunos faltem às aulas. Os resultados são apresentados no gráfico 2.

Gráfico 2 - Atitudes adotadas para evitar que os alunos faltem as aulas 


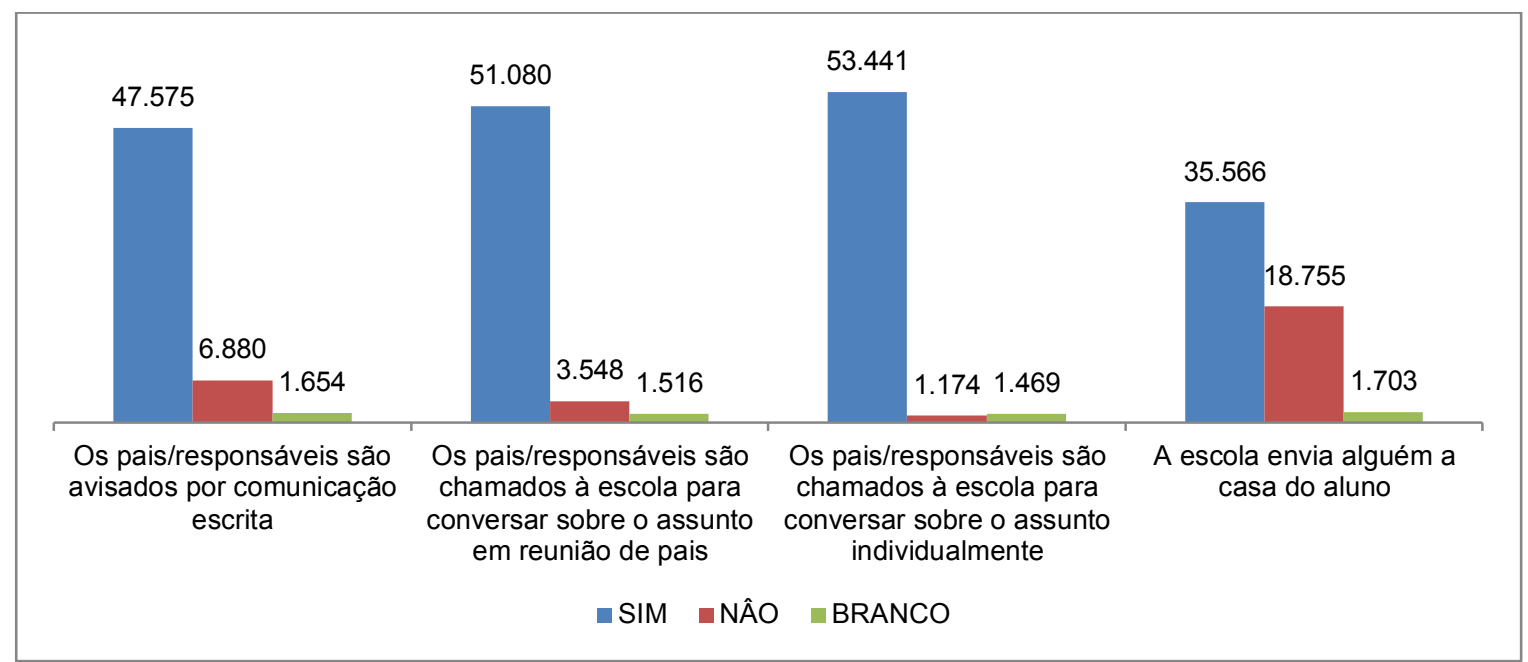

Fonte: Elaboração das autoras, 2014

Essas respostas sugerem trabalho da escola no sentido de promover a mobilização dos pais, uma vez que:

- $84,8 \%$ informa que os pais/responsáveis são avisados por comunicação escrita.

- $91,0 \%$ afirma que os pais/responsáveis são chamados à escola para conversar sobre $o$ assunto em reunião de pais.

- 95,3\% responde que os pais/responsáveis são chamados à escola para conversar sobre o assunto individualmente.

- $63,5 \%$ registra que a escola envia alguém à casa do aluno.

A chamada dos pais à escola, para envolvê-los no acompanhamento da vida escolar de seus filhos parece se configurar numa iniciativa positiva de aproximação das famílias à escola, a depender do conteúdo e da forma de conduzir tais abordagens.

Outra indagação do questionário do diretor diz respeito à utilização dos espaços da escola para atividades comunitárias e a forma como isso ocorre. Os dados sobre o assunto são apresentados no gráfico 3 .

Gráfico 3 - Forma de utilização dos espaços da escola para atividades comunitárias 


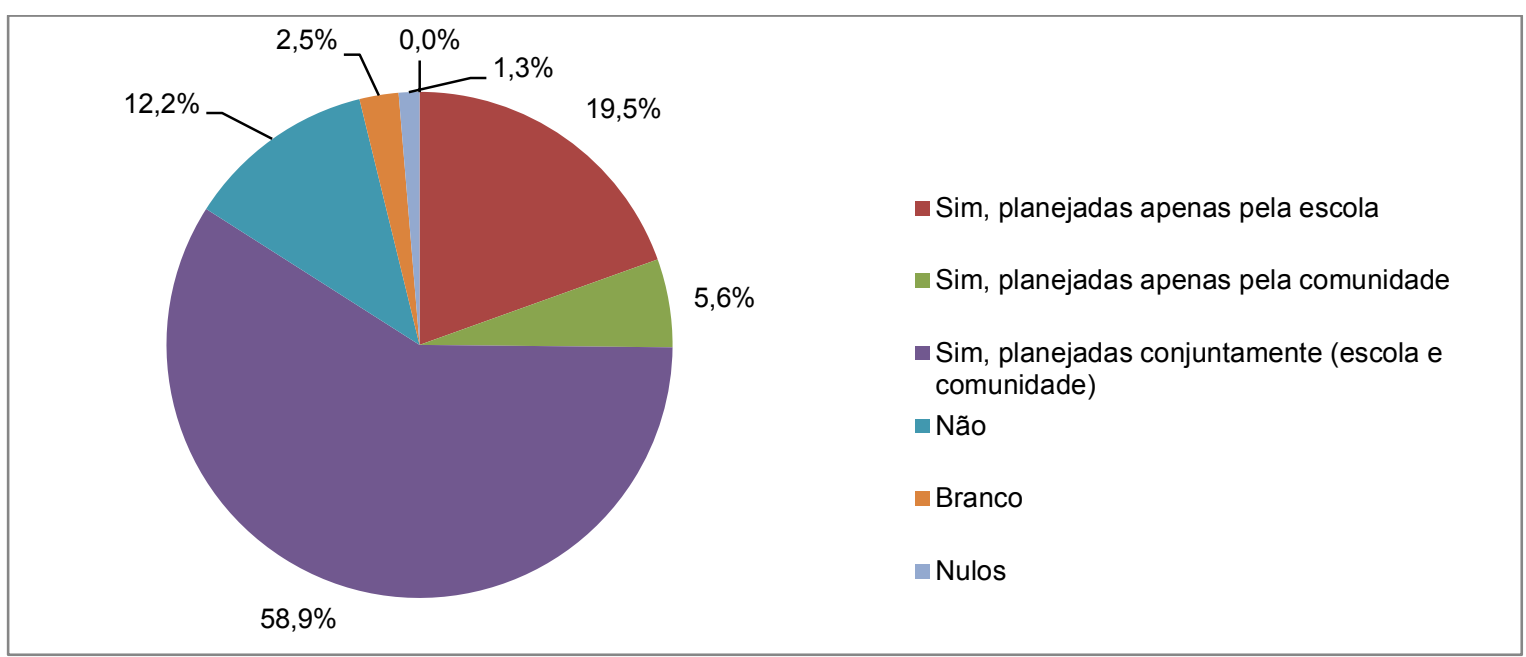

Fonte: Elaboração das autoras, 2014

Como é possível observar, $58,9 \%$ dos diretores afirma que o uso dos espaços da escola é planejado conjuntamente com a comunidade; $19,5 \%$ afirma que as atividades são planejadas apenas pela escola e 12,2\% informa que a comunidade não utiliza os espaços da escola.

Finalmente, oito questões são dedicadas a investigar o tipo de evento que aconteceu na escola em 2011, cujos dados são apresentados no quadro 1. 
Quadro 1 - Tipos de eventos que ocorreram na escola e público-alvo

\begin{tabular}{|c|c|c|c|c|c|}
\hline Neste ano ocorreram na escola & Sim & Não & Branco & Nulos & Total \\
\hline $\begin{array}{l}\text { Eventos da comunidade usando instalações, equipamentos } \\
\text { ou recursos da escola. }\end{array}$ & 35.749 & 18.823 & 1.351 & 299 & 56.222 \\
\hline $\begin{array}{l}\text { Eventos de terceiros realizados na escola e abertos para a } \\
\text { comunidade. }\end{array}$ & 28.943 & 25.768 & 1.322 & 189 & 56.222 \\
\hline Eventos da escola e destinados à comunidade externa. & 39.460 & 15.238 & 1.329 & 195 & 56.222 \\
\hline Campanhas de solidariedade promovidas pela escola. & 31.415 & 23.236 & 1.326 & 245 & 56.222 \\
\hline $\begin{array}{l}\text { Campanhas de solidariedade proposta pela comunidade, } \\
\text { envolvendo a escola. }\end{array}$ & 22.602 & 32.063 & 1.378 & 179 & 56.222 \\
\hline $\begin{array}{l}\text { Comunidade colaborando na manutenção de hortas, } \\
\text { pomar, jardins. }\end{array}$ & 8.965 & 45.740 & 1.333 & 184 & 56.222 \\
\hline $\begin{array}{l}\text { Comunidade participando em mutirão para limpeza da } \\
\text { escola. }\end{array}$ & 9.201 & 45.571 & 1.315 & 135 & 56.222 \\
\hline $\begin{array}{l}\text { Comunidade participando em mutirão para manutenção da } \\
\text { estrutura física da escola. }\end{array}$ & 7.762 & 47.026 & 1.313 & 121 & 56.222 \\
\hline
\end{tabular}

Fonte: Elaboração das autoras, 2014

Nesse caso, as respostas dos diretores mostram que:

- $70,2 \%$ dos eventos ocorridos na escola foram destinados à comunidade externa.

- $63,6 \%$ dos eventos ocorridos na escola envolveu a comunidade usando instalações, equipamentos ou recursos da escola.

- $55,9 \%$ das escolas promoveu campanhas de solidariedade.

- $51,5 \%$ afirmou ocorrer na escola eventos de terceiros abertos para a comunidade.

- $40,2 \%$ informou ter havido na escola campanhas de solidariedade propostas pela comunidade, envolvendo a escola.

- $16,4 \%$ respondeu que aconteceram eventos com a comunidade participando em mutirão para limpeza da escola.

- $15,9 \%$ afirmou que ocorreram eventos com a comunidade colaborando na manutenção de hortas, pomar, jardins.

- $13,8 \%$ registrou que ocorreu eventos com a comunidade participando em mutirão para manutenção da estrutura física da escola.

Uma análise dos resultados apresentados no quadro 1 mostra que a relação escola e comunidade está em avançado processo de parceria. Observa-se, no 
entanto, que na maioria das situações, a escola atua como protagonista, cabendo à comunidade, um papel mais coadjuvante. Outro destaque são os baixos percentuais de participação da comunidade em atividades que envolvem a melhoria das condições de infraestrutura da escola, como mutirão de limpeza (16,4\%), manutenção de hortas, pomares e jardins $(15,9 \%)$ e manutenção da estrutura física da escola $(13,8 \%)$.

No que diz respeito ao questionário dos professores, conforme já observado, as perguntas que abordam a questão da participação da família, se referem a dificuldades no processo ensino-aprendizagem.

Quadro 2 - Causas associadas a problemas de aprendizagem dos alunos

\begin{tabular}{|l|c|c|c|c|l|}
\hline $\begin{array}{l}\text { Problemas de aprendizagem dos alunos } \\
\text { são decorrentes }\end{array}$ & Concordo & Discordo & Branco & Nulos & Total \\
\hline Do meio em que o aluno vive & 183.462 & 40.789 & 77.811 & 2.350 & $\mathbf{3 0 4 . 4 1 2}$ \\
\hline Do nível cultural dos pais dos alunos & 166.683 & 58.749 & 78.487 & 493 & $\mathbf{3 0 4 . 4 1 2}$ \\
\hline $\begin{array}{l}\text { Estão relacionados a falta de assistência e } \\
\text { acompanhamento da família nos deveres de } \\
\text { casa e pesquisa dos alunos }\end{array}$ & 214.537 & 11.032 & 78.242 & 610 & $\mathbf{3 0 4 . 4 2 1}$ \\
\hline
\end{tabular}

Fonte: Elaboração das autoras, 2014

Os dados evidenciam a responsabilização que os docentes atribuem às famílias e ao entorno extraescolar acerca das dificuldades de aprendizagem dos alunos. Esse fato corrobora estudos que atribuem ao nível socioeconômico do aluno, a responsabilidade pelo sucesso ou fracasso escolar, minimizando o papel e a capacidade da escola na reversão dessa situação.

Analisados os dados da Prova Brasil sobre a relação entre a escola e seu entorno social, é momento de refletir sobre aquilo que os educadores costumam caracterizar como o "chão da escola" e mostrar que esta é uma relação por demais delicada. Seria oportuno afirmar que a sintonia entre a escola e a comunidade, de algum modo, está associada à relevância que ela consegue imprimir no território onde se insere. A experiência de investigação (CENPEC, 1993; VIEIRA et al., 1999, 2011; VIEIRA; MATOS; MAIA, 2000) revela haver algo indizível nesta relação, que ultrapassa as meras fronteiras da racionalidade. 
Pesquisas recente de grupos aos quais as autoras estão vinculadas (VIDAL; VIEIRA, 2014; VIDAL, VIEIRA; MEDEIROS, 2014) desenvolvidas no âmbito de projeto de investigação sobre 15 municípios na região do Maciço de Baturité - Ceará (VIEIRA et al., 2011),contemplou questões sobre o tema. Das entrevistas realizadas com dirigentes escolares, constava uma questão específica sobre a relação escolacomunidade.

De uma maneira geral, todos afirmaram o caráter positivo deste vínculo. Entretanto, dispersos por entre outros temas das dificuldades enfrentadas pelos diretores, a relação com a família aparece como um nó ainda não suficientemente dissolvido. As falas permitiram perceber ecos de visões expressos em estudos anteriores e em representações sobre esta delicada relação. O não engajamento por parte das famílias é percebido como uma questão problemática. Isto porque, segundo os dirigentes escolares: "A gente sempre acaba colocando a culpa em

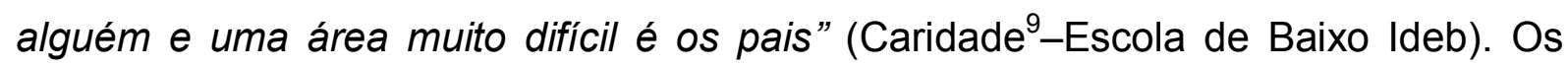
recortes a seguir dizem algo de tais impressões.

Trazer os pais para a escola não é empreitada simples. Muitos relatam que a própria presença de muitas crianças está associada à exigência do Programa Bolsa Família (iniciativa de transferência direta de renda do governo federal que vincula o recebimento do recurso à frequência escolar):

"80\% das nossas crianças recebem bolsa família, então assim o que assegura ainda essa presença do aluno que caiu muito o índice de evasão, repetência foi graças a essa bolsa família, agora é aquela história, a família joga a criança dentro da escola, a escola que tem que se virar com ela, é isso ai que a gente sente aquela falta do pai ir lá na escola e saber uma atividade de casa" (Caridade-Escola de Alto Ideb)

"É difícil a participação. Nós mandamos bilhete, muitas vezes a gente chega até a falar que vai ter o cadastro do Bolsa Família e a gente vai ter que ter a assinatura deles, a presença deles e a participação na escola e até que eles

\footnotetext{
${ }^{9}$ Um dos quinze municípios que compõe o estudo realizado no estado do Ceará.
} 
ainda vêm. Mas é muito difícil trazer os pais para dentro da escola"(Baturité ${ }^{10}$ Escola de Alto Ideb)

A participação dos pais, em geral, se restringe àqueles que já acompanham a vida de seus filhos, como se vê no depoimento de uma diretora:

"Os pais mais frequentes são daqueles alunos que a gente chama de 'tudo de bom', e os alunos que dão mais trabalho, são esses pais que a gente não consegue trazer quando a gente mais precisa, esses são nossos desafios" (Guaramiranga ${ }^{11}-$ J.H).

Os pais das crianças que mais precisam da escola parecem ser os mais avessos à participação:

"Tem pais que quer saber se ele esta ali, mas não vem aqui nem pra saber. Principalmente os pais daquelas crianças que não são assim consideradas como hiperativas, consideradas danadas. Eles parecem que tem é medo ou que não gostam de ouvir assim uma reclamaçãozinha do filho, daí a gente não consegue muito trazer pra escola" (Barreira ${ }^{12}$-Escola de Alto Ideb).

Há uma compreensão de que os pais não se aproximam da escola por razões diversas:

"Eu acho que muitas vezes não se sentem parte da escola. Nós fazemos aqui gincanas, fazemos a feira cultural, mandamos convidar e alguns pais vêm, mas são sempre aqueles pais que os meninos são excelentes e que não dá trabalho. Não é o pai que realmente precisava vim para ver. Não é que a gente quisesse reclamar deles. A gente queria que eles se entrosassem e podia ser que eles gostando da escola os filhos viessem a gostar. Eu acho que deveria ter para todas as escolas uma pessoa para trabalhar com as

\footnotetext{
${ }^{10} U m$ dos quinze municípios que compõe o estudo realizado no estado do Ceará.

${ }^{11} U \mathrm{~m}$ dos quinze municípios que compõe o estudo realizado no estado do Ceará.

${ }^{12} U m$ dos quinze municípios que compõe o estudo realizado no estado do Ceará.
} 
famílias e trazer as famílias para as escolas. É isso"(Aracoiaba ${ }^{13}$-Escola de Alto Ideb).

Inúmeros outros depoimentos poderiam ser acrescentados no sentido de aprofundar a compreensão sobre a delicadeza da relação entre a escola e seu entorno social. A matéria, porém, já nos oferece elementos para compreender que esta é também uma construção histórica e complexa.

É importante também destacar que a universalização da escola para as camadas sociais menos favorecidas é fenômeno recente. Os pais dessa geração que está frequentando a escola, muitas vezes não concluíram uma etapa completa de escolaridade. A compreensão de certas sutilezas do fenômeno educativo, por vezes, escapa à compreensão desses sujeitos.

$O$ reconhecimento das condicionalidades sobre frequência escolar, impostas pelo Programa Bolsa Família, evidencia o que os dados de Censo Escolar (INEP) vêm mostrando ano à ano, no que tange à diminuição das taxas de evasão e abandono, mas não aponta o mesmo cenário alvissareiro sobre a taxa de reprovação, que ainda sobrevive próximo a $10 \%$ em 2013. Ou seja, o acesso e a permanência a escola é assegurado, no entanto, o sucesso escolar ainda representa um desafio para as crianças mais vulneráveis socialmente.

Os dados também revelam que a escola vem funcionando como um equipamento público proativo, tomando atitudes de mobilização das famílias em torno de um projeto educativo que procura fortalecer a participação da comunidade $e$ a melhoria dos serviços educacionais oferecidos. No entanto, a repercussão de suas iniciativas ainda não alcançou o eco desejado ou esperado, o que pode estar associado a fatores históricos, explicados por Celso Furtado ao analisar a construção da sociedade brasileira, e concluir que "O Brasil é uma criação do Estado português. Não se trata de uma sociedade que construiu um Estado e sim de um Estado que constituiu uma sociedade" (apud MATIJASCIC, 2010, p. 9), o que pode contribuir para elucidar a assimetria da relação escola-família.

Os nexos entre as partes envolvidas não resultam de meros atos ou decretos do Executivo. Tal aproximação, com efeito, é fruto do compromisso político que os

\footnotetext{
${ }^{13} \mathrm{Um}$ dos quinze municípios que compõe o estudo realizado no estado do Ceará.
} 
diferentes atores trazem para esta arena de participação. Se há empenho dos envolvidos, relações mais próximas podem florescer, repercutindo sobre a qualidade do trabalho escolar. Se, ao contrário, prevalece um clima formal onde pais e comunidade, quando muito, referendam o que a escola faz, tal relação é incipiente e pouco, ou nada, acrescenta. O todo, com efeito, é maior que a soma das partes. $\mathrm{E}$ cada parte tem um papel que lhe é próprio e não se confunde com as demais. A escola precisa querer se aproximar do seu entorno; o entorno, por sua vez, precisa querer se aproximar da escola. Neste jogo de desvelamento mútuo, algo de bom pode acontecer. Como vimos na pesquisa sobre os questionários da Prova Brasil 2011 com diretores e professores, a relação escola e comunidade ainda é assimétrica, atuando a escola como a protagonista das iniciativas.

A imersão em processos de pesquisa permite constatar que quanto mais pobre a comunidade, maior a importância da escola em relação a seu entorno. E, assim sendo, é precipitado antecipar a complexidade da dinâmica que irá se instaurar. Tanto a escola pode configurar-se como um oásis de paz em um território de segregação social como tornar-se refém de um entorno violento. A construção de uma ou outra alternativa são possibilidades postas aos atores em cena. Assim, para estreitar a relação entre a escola e seu entorno, é preciso escolher entre permanecer onde se está ou ir além. Como síntese, pode-se dizer que embora o tema tenha estado presente na literatura e nas cogitações da política educacional há pelo menos uma década, permanece como uma questão em aberto.

\section{SOFIA LERCHE VIEIRA}

Doutora em Filosofia e História pela Pontifícia Universidade de São Paulo (PUC/SP). Pós-doutorado pela Universidad Nacional de Educacion a Distancia (UNED). Bolsista de produtividade do CNPq, professora do Programa de Pós-Graduação em Educação da Universidade Nove de Julho (Uninove) e da Universidade Estadual do Ceará (UECE).

\section{ELOISA MAIA VIDAL}

Doutora em Educação pela Universidade Federal do Ceará (2000), professora adjunta da Universidade Estadual do Ceará. 


\section{REFERÊNCIAS}

ATHIAS, G. Dias de paz: a abertura das escolas paulistas para a comunidade. 2.ed. Brasília: UNESCO, Fundação Vale, 2008, 137 p. Disponível em <http://unesdoc.unesco.org/images/0017/001785/178541por.pdf>. Acesso em: 14 out. 2012.

BRASIL. Presidência da República. Casa Civil. Subchefia para Assuntos Jurídicos. Constituição da República Federativa do Brasil de 1988. Disponível em https://www.planalto.gov.br/ccivil_03/Constituicao/Constituicao.htm. Acesso em Acesso em: 18 out. 2014.

BRASIL. Presidência da República. Casa Civil. Subchefia para Assuntos Jurídicos. Lei $n^{\circ}$ 9.394, de 20 de dezembro de 1996 (LDB). Estabelece as diretrizes e bases da educação nacional. Disponível em:

<http://www.planalto.gov.br/ccivil_03/leis//9394.htm>. Acesso em: 01 abril 2015.

BRASIL. FNDE. Resolução $n^{\circ} 18$ de 3 de setembro de 2014. Disponível em: <https://www.fnde.gov.br/fndelegis/action/UrlPublicasAction.php?acao=abrirAtoPubli co\&sgl_tipo $=R E S \& n u m \_a t o=00000018 \& s e q \_a t o=000 \& v \mid r+a n o=2014 \& s g l$ orgao $=C D$ /FNDE/MEC>. Acesso em: 08 maio 2015.

BRASIL. INEP. Microdados Prova Brasil. Disponível em: <http://portal.inep.gov.br/ basica-levantamentos-acessar>. Acesso em: 18 out. 2014.

BRASIL. MEC. Conselhos Escolares - Formação. Disponível em: <http://portal.mec.gov.br/index.php?option=com_content\&view=article\&id=14805\&lte mid=1054>. Acesso em: 18 out. 2014.

BRASIL. MEC. Banco de Experiências de Conselhos Escolares. Disponível em: <http://bancodeexperienciasce.mec.gov.br/relato/lista>. Acesso em: 18 out. 2014.

BRASIL. MEC. Programa Escola Aberta. Disponível em:<http://portal.mec.gov.br/ index.php?option=com_content\&view=article\&id=16739\&/te mid=811>. Acesso em: 18 out. 2014.

BROOKE, N.; SOARES, J. F. (orgs.).Pesquisa em eficácia escolar: origem e trajetórias. Belo Horizonte: Editora UFMG, 2008, 552 p.

CASTRO, J. M.; REGATTIERI, M. (orgs.). Interação escola-familia: subsídios para práticas escolares. Brasília: Unesco, MEC, 2009, 104 p. Disponível em: <http://unesdoc.unesco.org/images/0018/001877/187729POR.pdf>. Acesso em: 14 out. 2012.

CENPEC.A democratização do ensino e a organização comunitária: a experiência de Iguatu-CE; 1989/1992. São Paulo: Cenpec/Unicef, 1993. 
CLEWELL, B. C.; CAMPBELL, P. B.; PERLMAN, L. Good schools in poor neighborhoods.Washington, The Urban Institute Press, 2007.268p.

EUROPEAN CONSORTIUM. Parents participation.eu our human rights vision.

Disponível em:<http://www.parentsparticipa tion.eu/en/observatory/presentation>. Acesso em: 18 out. 2104.

EYZAGUIRRE, B. Claves para la educación en pobreza. Estudios públicos. Verano 2004, p. 249-277. Disponível em:<http://www.educarenpobreza.cl/Userfiles/ p0021/file/educación_en_pobreza._b._eyzaguirre.pdf>.Acesso em: 11 set. 2012.

GERTLER, P.; PATRINOS, H.; RUBIO-CODINA, M. Empowering parents to improve education: evidence from rural Mexico. World Bank Policy Research Working.Paper 3935, Revised May, 2008.Disponível em:<http://www.cid.

harvard.edu/neudc07/docs/neudc07_s1_p09_gertler.pdf>. Acesso em: 14 out. 2012.

INEP. Sinopse Estatística da Educação Básica 2013. Disponível em:

$<$ http://portal.inep.gov.br/basica-censo-escolar-sinopse-sinopse>.Acesso em:08 maio 2015.

MATIJASCIC, M. (org).Estado versus mercado: falsas disjuntivas e a natureza dos fenômenos sob um olhar da história. In: IPEA. Presença do Estado no Brasil:

federação, suas unidades e municipalidades. 2. ed. rev. e ampl. Brasília: Ipea, 2010, p. $9-13$.

NYE, C.; SCHWARTZ, J.; TURNER, H. Approaches to Parent Involvement for Improving the Academic Performance of Elementary School Age Children. Campbell Systematic Reviews.2006, 49 p. Disponívelem:<http://www.

campbellcollaboration.org/library.php>.Acesso em: 04 out. 2012.

REDDING, S. Parents and learning. UNESCO. IAE. s/d. Disponível

em:<http://www.ibe.unesco.org/publications/EducationalPracticesSeriesPdf/prac02e. pdf>Acesso em: 02 out. 2012.

ROSE, P. Communities, gender and education: evidence from sub-Saharan Africa. Background paper for 2003UNESCO Global Monitoring

Report.Disponívelem:<http://unesdoc.unesco.org/images/0014/001469/146930e.pdf> .Acessoem: 04 out. 2012.

SHAEFFER, S. Participation for educational change: a synthesis of experience.

Paris, UNESCO: International Institute for Educational Planning, 1994, 194 p.

Disponível em: <http://www.unesco.org/pv_obj_cache/pv_obj_id_2A3CABCF756FE 47F38E4BBF4636A759F8C791800/filename/11_197.pdf >.Acesso em: 14 out. 2012.

TODOS PELA EDUCAÇÃO. Eu, Você, Todos Pela Educação. 8 vídeos. Disponível em: <http://www.todospelaeducacao.org.br/noticias-tpe/tvtpe/?tipoMaterial=\&pag=2>. Acesso em: 18 out. 2014. 
UEMURA, M. Community Participation in Education: What do we know? Effective Schools and Teachers and the Knowledge Management System. HDNED, The World Bank, 1999.Disponívelem:<http://siteresources.worldbank.org/ INTISPMA/Resources/383704-1153333441931/14064_Community_Participation_in _Education.pdf>.Acesso em: 04 out. 2012.

UNESCO. Declaração Mundial de Educação para Todos: satisfação das necessidades básicas de aprendizagem. Jomtien, 1990. Disponível em: <http://unesdoc.unesco.org/images/0008/000862/086291por.pdf>.Acesso em: 04 out. 2012.

VIDAL, E. M.; VIEIRA, S. L. Educação e território 1: contribuições para o debate na região do Maciço do Baturité. Fortaleza:Liber Livro, 2014.228p.

VIDAL, E. M.; VIEIRA, S. L.; MEDEIROS, W. N. Educação e território 2: subsídios ao planejamento de políticas municipais na região do Maciço do Baturité.

Fortaleza:Liber Livro, 2014. 268p.

VIEIRA, S. L.et al. Observatório da Educação no Maciço de Baturité. Projeto de pesquisa. Edital Universal no 14/2011. CNPq: Fortaleza, 2011, mimeo.

. Educação, escola e comunidade: um estudo-piloto no estado do Ceará. Brasília: Projeto Nordeste, 1999.

VIEIRA, S. L.; MATOS, K. L.;MAIA, M. H.Ceará - qualidade, acesso e gestão na escola: uma visão dos usuários. Brasília: Banco Mundial, 2000. 